\title{
Analisa Tingkat Penerimaan Pengguna Terhadap Aplikasi SIMPUS dengan Metode Technology Acceptance Model (TAM)
}

\author{
Sri Mulyono ${ }^{1}$, Wahyul Amien Syafei ${ }^{2}$, Retno Kusumaningrum ${ }^{3}$ \\ Magister Sistem Informasi, Universitas Diponegoro Semarang \\ Jl. Imam Bardjo, SH No 5 Semarang 50241, Telp./Fax:02488448610 \\ e-mail: ${ }^{1}$ srimulyonostikes@gmail.com, ${ }^{2}$ wasyafei@gmail.com, ${ }^{3}$ retno_309352@yahoo.co.id
}

Diterima: 10 Januari 2020; Direvisi: 31 Mei 2020; Disetujui: 31 Mei 2020

\begin{abstract}
Abstrak
Penelitian ini bertujuan melakukan Analisa Tingkat Penerimaan PenggunaTerhadap pengguna Apikasi Sistem Informasi Manajemen Puskesmas SIMPUS dengan metode TAM. Variabel yang digunakan yaitu persepsi tentang kemudahan (Perseive ease of use), Persepsi terhadap kemanfaatan (Perceived Usefulness), Sikappenggunaan (Attitude Toward Using), Perilaku untuk tetap menggunakan (Behavioral Intention To Use), Kondisi nyata pengguna sistem (Actual System Usage).Bahan dan alat penelitian adalah Aplikasi SIMPUS.Teknik pengumpulan data dengan observasi dan penyebaran kuisioner tertutupsejumlah 110 kuisioner kepada 110 pengguna aplikasi SIMPUS sebagai sampel.Hasil penelitian menunjukan pada data keenam variable berdistribusi normal (nilai Sig > 0.05) yaitu X1 $(p=0,172), X 2 \quad(p=0,171), X 3$ $(p=0,143), X 4(p=0,117), X 5(p=0,062), Y(p=0,592)$. Hasil Uji Linearitas dengan menggunakan uji Durbin Watson menunjukkan bahwa tidak auto korelasi atau asumsi terpenuhi bahwa fungsi linier yaitu nilai statistic Durbin Watson $(1,722)$ terletak diantara nilai table Durbin Watson $(1,703)$ dan $4-D U(2,291)$.Hasil Uji multikolinieritas menunjukkan bahwa tidak ada satu pun variable bebas yang memiliki nilai VIF(variance inflation factor) lebih dari 10 atau nilai toleransi kurang dari 0,10. Dan nilai $F_{\text {hitung }}=91,469>F_{\text {tabel }}=2,65$ atau nilai $p<0,05$. Variabel $X_{1}, X_{2}, X_{3}, X_{4}$, $X_{5}$ berpengaruh secara simultan atau bersama - sama dan signifikan terhadap penerimaan SIMPUS.Kesimpulan aspek persepsi kemudahan, persepsi kegunaan,sikap menggunakan, memberikan pengaruh nyata terhadap penerimaan SIMPUS. Sedangkan niat perilaku menggunakan, penggunaan SIMPUS sesungguhnya tidak berpengaruh terhadap penerimaan SIMPUS.
\end{abstract}

Keywords: SIMPUS, Teknology Acceptance Model, Regresi Linier Berganda.

\begin{abstract}
This study aims to analyze the level of user acceptance of users of the SIMPUS Puskesmas Management Information System application using the TAM method. The variables used are perceptions of ease (Perceive ease of use), Perceived Usefulness, Attitude Toward Using, Behavioral Intention To Use, Actual System Usage. Materials and research tools are the SIMPUS Application. Data collection techniques with observation and distribution of closed questionnaires totaling 110 questionnaires to 110 SIMPUS application users as a sample. The results of the study show the data of the six variables with normal distribution (Sig value $>0.05)$ namely XI ( $p=$ $0.172), X 2(p=0.171), X 3(p=0.143), X 4(p=0.117), X 5(p=0.062), Y(p=0.592)$. Linearity Test Results using the Durbin Watson test show that there is no auto correlation or assumptions fulfilled that the linear function is the Durbin Watson statistical value $(1,722)$ located between the Durbin Watson table values $(1,703)$ and 4 - DU (2,291). The results of the multicollinearity test
\end{abstract}


show that there is no single variable A free le has a VIF (variance inflation factor) value of more than 10 or a tolerance value of less than 0.10. And the value of Fcount $=91.469>$ Ftable $=2.65$ or $p$ value $<0.05$. Variables $X 1, X 2, X 3, X 4, X 5$ have an effect simultaneously or together and are significant to the reception of SIMPUS. Conclusion aspects of perceptions of ease, perceived usefulness, attitude of using, giving a real influence on the reception of SIMPUS. While the behavioral intention to use, SIMPUS usage actually has no effect on SIMPUS acceptance.

Keywords: SIMPUS, Technology Acceptance Model, Multiple Linear Regression.

\section{PENDAHULUAN}

Sistem informasi merupakan bagian penting dalam suatu organisasi, termasuk puskesmas. SIMPUS diharapkan dapat meningkatkan manajemen puskesmas secara lebih berhasilguna dan berdayaguna melalui pemanfaatan secara optimal dari sistem pencatatan pelaporan terpadu puskesmas (SP2TP). Menurut DepKes RI [1] SIMPUS merupakan kegiatan aplikasi yang digunakan dalam kegiatan di puskesmas kegiatan di luar gedung maupun di dalam gedung dengan menggunakan koneksi database secara online atau offline. Juga merupakan pengertian dari Panduan Penggunaan SIKDA Generik Puskesmas [1]. Dalam analisa yang dilakukan tangke [2] penerapan teknologi informasi dalam jajaran pemerintahan khususnya di dinas kesehatan berpengaruh pada keseluruhan organisasi terutama pada sumber daya manusianya. Faktor sumber daya manusia sebagai pengguna sistem informasi sangat penting untuk diperhatikan dalam penerapan sistem baru, karena tingkat kesiapan penggunaan untuk menerima sistem baru mempunyai pengaruh besar dalam menentukan sukses dan tidaknya pengembangan sistem tersebut.

Pada penelitian ini mengenai analisa tentang tingkat penerapan pengguna SIMPUS menggunakan metode Technology Acceptance Model (TAM) [3]. Peniliti menggunakan variabel yang telah dimodifikasi dari model tam yaitu : Persepsi tentang kemudahan penggunaan (Perseive Ease Of Use), persepsi terhadap kemanfaatan (Perceived Usefulness), sikap penggunaan (Attitude Toward Using),perilaku untuk tetap menggunakan (Behavioral Intention To Use), kondisi nyata pengguna system (Actual System Usage), penerimaan SIMPUS (Acceptance SIMPUS). Penelitian ini juga ingin mengetahui tujuan pengguna yang merujuk pada penelitian [4] serta [5] dengan mengidentifikasi faktor penentu. Dan [6] sama-sama mengindentifikasi faktor yang mempengaruhi dengan menggunakan agresi linier.

\section{METODE OPTIMASI}

Menurut Morris dan Dillon [7] TAM adalah sebuah model untuk memprediksi bukan mendiskripsikan, yang digunakan untuk memprediksikan penerimaan dari sistem user. Dalam penelitian ini memadukan model penerimaan teknologi dengan menggunakan TAM dengan memadukan lima variable. Peniliti menggunakan variabel yang telah dimodifikasi dari model tam yaitu : Persepsi tentang kemudahan penggunaan (Perseive Ease Of Use), persepsi terhadap kemanfaatan (Perceived Usefulness), sikap penggunaan (Attitude Toward Using),perilaku untuk tetap menggunakan (Behavioral Intention To Use), kondisi nyata pengguna system (Actual System Usage), penerimaan SIMPUS (Acceptance SIMPUS) yang terdapat pada gambar 1.

Pada penelitian ini akan digunakan 5 variabel yang telah di modifikasikan model TAM [8]:

1. Persepsi Kemudahan (Perceived Ease Of Use) berpengaruh terhadap penerimaan (Acceptance Of SIMPUS).

2. Persepsi kegunaan (Perceived Usefulness) berpengaruh terhadap penerimaan (Acceptance Of SIMPUS). 
3. Sikap menggunakan SIMPUS (Attitude Toward Using) berpengaruh terhadap penerimaan (Acceptance Of SIMPUS).

4. Niat Perilaku Menggunakan SIMPUS (Behavioral Intention To Use) berpengaruh terhadap penerimaan (Acceptance Of SIMPUS).

5. Penggunaan SIMPUS sesungguhnya (Actual Use).berpengaruh terhadap penerimaan (Acceptance Of SIMPUS).

Evaluasi masing masing hasil diukur dengan skala ordinal dengan pendekatan 5 point likert Sekaran [9]. Alternatif jawaban yang diberikan adalah:

$\begin{array}{lll}\text { STS } & \text { : Sangat Tidak Setuju } & =\text { Nilai } 1 \\ \text { TS } & \text { : Tidak Setuju } & =\text { Nilai } 2 \\ \text { KS } & \text { : Kurang Setuju } & =\text { Nilai } 3 \\ \text { S } & \text { : Setuju } & =\text { Nilai } 4 \\ \text { SS } \quad \text { : Sangatsetuju } & =\text { Nilai } 5\end{array}$

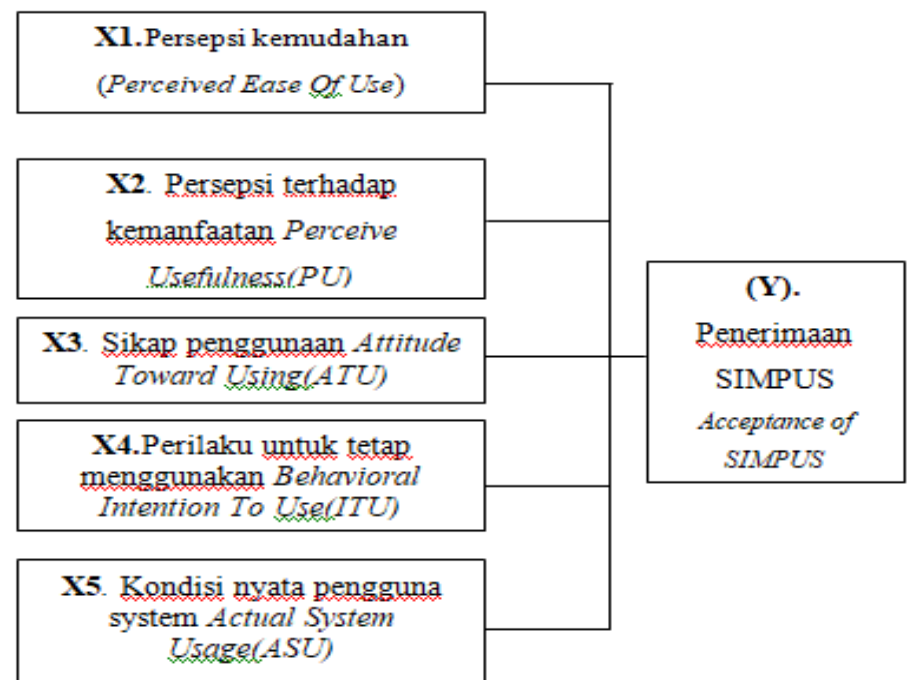

Gambar 1. Metode Penelitian

Dalam penelitian ini merujuk sebagian pada peneltian yang di teliti oleh Chen Lo [10] diadopsi dengan metode TAM untuk memahami sikap pengguna. Juga pada teori sikap oleh Jogiyanto [11] mengenai sikap perilaku.

\section{METODE ANALISIS DATA}

\subsection{Uji Statistik Deskripsi}

Statistik deskriptif merupakan statistik yang bertugas mendiskripsikan atau memaparkan gejala hasil penelitian. Uji statistik ini bertujuan mengetahui jumlah, mean, persentase variabel.

\subsection{Analisis Regresi Linier Berganda}

Analisis regresi merupakan suatu teknik untuk menentukan ketergantungan satu variabel dependent dengan satu atau lebih variabel independent. Regresi berganda digunakan untuk melihat pengaruh persepsi kemudahan (Perceived Ease Of Use) (x1), persepsi kegunaan (Perceived Usefulness) (x2), sikap menggunakan SIMPUS (Attitude Toward Using) (x3), niat perilaku menggunakan SIMPUS (Behavioral Intention To Use) (x4), penggunaan SIMPUS sesungguhnya (Actual Use) (x5), terhadap penerimaan SIMPUS (Acceptance Simpus)(y). Model tersebut dirumuskan dalam persamaan 1 sebagai berikut : 
$Y=a+b 1 x 1+b 2 \times 2+b 3 \times 3+b 4 x 4+b 5 x 5+e$

dimana :

$\mathrm{Y} \quad=$ acceptance simpus

$\mathrm{A} \quad=$ konstanta

$\mathrm{B}_{1} \quad=$ koefisien $\mathrm{x}_{1}$

$\mathrm{B}_{2} \quad=$ koefisien $\mathrm{x}_{2}$

$\mathrm{B}_{3} \quad=$ koefisien $\mathrm{x}_{3}$

$\mathrm{B}_{4} \quad=$ koefisien $\mathrm{x}_{4}$

$\mathrm{B}_{5} \quad=$ koefisien $\mathrm{x}_{5}$

$\mathrm{X}_{1} \quad=$ kemudahan

$\mathrm{X}_{2} \quad=$ kegunaan

$\mathrm{X}_{3} \quad=$ sikap menggunakan

$\mathrm{X}_{4} \quad$ = perilaku menggunakan

$\mathrm{X}_{5} \quad=$ pengguna sesungguhnya

$\mathrm{E}=$ error disturbances A. Uji t

Hasil persamaan regresi tersebut kemudian dianalisis dengan menggunakan beberapa uji:

Uji t dimaksudkan untuk mengetahui seberapa jauh pengaruh satu variable independen (kemudahan,kegunaan, sikap menggunakan, pengguna sesungguhnya) secara individual dalam menerangkan variable dependen (penerimaan simpus). Uji t dilakukan dengan membandingkan nilai t hitung dengan $t$ tabel. Kriteria ujinya adalah apabila nilai statistik $t$ hitung perhitungannya lebih tinggi dibandingkan nilai $t$ tabel, atau sig $t \leq 0,05$ maka ho ditolak. Tingkat signifikansi yang digunakan dalam penelitian ini adalah 5\%.rumus uji t pada rumus persamaan 2 dibawah ini:

$$
t=\frac{r \sqrt{n-2}}{\sqrt{1-r^{2}}}
$$

dimana:

$\mathrm{T}=\mathrm{t}$ Hitung yang selanjutnya dikonsultasikan dengan $\mathrm{t}$ table

$\mathrm{R}=$ Korelasi parsial yang ditentukan

$\mathrm{N}$ = Jumlah sampel

B. Uji f

Uji f dipergunakan untuk menguji semua variabel bebas memiliki pengaruhterhadap variabel terikat. Kriteria ujinya adalah bila nilai $f$ hitung $>\mathrm{f}$ tabel atau sig. $\mathrm{f} \leq 0,05$, maka ho ditolak artinya variabel bebas (independent) secara bersama- sama berpengaruh signifikan terhadap variabel terikat ( dependent) dengan rumus pada persamaan 3 berikut:

$\mathrm{F}=\frac{R^{2} / \mathrm{k}}{\left(1-R^{2}\right) /(\mathrm{n}-\mathrm{k}-1)}$

dimana:

$\mathrm{F}=\mathrm{f}$ hitung yang selanjutnya dikonsultasikan dengan $\mathrm{f}$ table

$\mathrm{R}^{2}=$ Korelasi parsial yang ditemukan

$\mathrm{N}=$ Jumlah sampel

$\mathrm{K}=$ Jumlah variabel bebas

\section{Uji Koefisien Determinasi $\left(\mathrm{r}^{2}\right)$}

Uji koefisien determinasi $\left(\mathrm{r}^{2}\right)$ digunakan untuk mengukur seberapa jauh kemampuan variabel bebas dalam menerangkan variable terikat. 


\subsection{Uji Persyaratan / Asumsi}

\section{A. Uji Normalitas}

Uji normalitas yang digunakan dalam penelitian ini adalah uji kolmogorov - smirnov ( k- s). Kriteria ujinya adalah bila nilai sig $>0.05$, maka ho diterima yang berarti data residual berdistribusi normal. Analisis regresi mengasumsikan bahwa variabel pengganggu $\epsilon$ berdistribusi normal.

\section{B. Uji Linearitas}

Uji linearitas yang digunakan dalam penelitian ini adalah uji durbin watson. Kriteria ujinya adalah nilai uji statistik durbin watson terletak diantara du dan 4 - du maka ho diterima yang berarti autokorelasi negatif dan fungsi linier.

C. Uji Independensi (Uji Multikolinieritas)

Uji independensi digunakan untuk melihat apakah model regresi ditemukan adanya korelasi antar variabel bebas (independen). Hal ini dapat dilihat dari variance inflation faktor (vif), jika nilai vif di atas 10 maka dikatakan terdapat korelasi antar variabel independen atau terdapat multikolinieritas (korelasi yang besar antar variabel bebas).

\section{HASIL PENELITIAN DAN PEMBAHASAN}

Pada penelitian ini hasil yang dicapai adalah sistem informasi analisa tingkat penerimaan pengguna terhadap Apilkasi Sistem Informasi Manajemen Puskesmas (SIMPUS).

\subsection{Karakteristik Responden}

Perkiraan kebutuhan produksi diketahui dari jumlah permintaan pelanggan atau penjualan dan perhitungan bahan baku yang dibutuhkan untuk memproduksi suatu produk dengan jumlah persediaan.

Tabel 1. Distribusi responden berdasar gender

\begin{tabular}{llll}
\hline No & Gender & Frekuensi & Persentase $(\%)$ \\
\hline 1 & Pria & 17 & 32,1 \\
2 & Wanita & 36 & 67,9 \\
\hline Total & & 53 & 100 \\
\hline
\end{tabular}

Berdasarkan tabel 1 diketahui bahwa dari 53 sampel responden, sebanyak 67,9\% adalah wanita dan sisanya sejumlah $32,1 \%$ adalah pria. Selanjutnya distribusi responden berdasar jabatan, lama bekerja dan pendidikan ditunjukan dengan tabel 2,3,4 dibawah ini:

Tabel 2. Distribusi responden berdasar jabatan

\begin{tabular}{lllc}
\hline No & Jabatan & Frekuensi & Persentase $(\%)$ \\
\hline 1 & Mahasiswa magang & 9 & 17,0 \\
2 & Administrasi & 21 & 39,6 \\
3 & Bidan & 13 & 24,5 \\
4 & Dokter & 10 & 18,9 \\
\hline & Total & 53 & 100 \\
\hline
\end{tabular}

Tabel 3. Distribusi responden berdasar lama bekerja

\begin{tabular}{cllc}
\hline No & Lama Bekerja & Frekuensi & Persentase $(\%)$ \\
\hline 1 & $<3$ tahun & 38 & 71,7 \\
2 & $3-10$ tahun & 6 & 11,3
\end{tabular}




\begin{tabular}{cccc}
3 & $>10$ tahun & 9 & 17,0 \\
\hline Total & 53 & 100 \\
\hline
\end{tabular}

Tabel 4 Distribusi responden berdasar pendidikan

\begin{tabular}{llll}
\hline No & Pendidikan & Frekuensi & Persentase(\%) \\
\hline 1 & Mahasiswa & 12 & 22,6 \\
2 & SMU & 7 & 13,2 \\
3 & D3 & 19 & 35,8 \\
4 & S1/d4 & 12 & 22,6 \\
5 & S2 & 3 & 5,7 \\
\hline & Total & 53 & 100 \\
\hline
\end{tabular}

\subsection{Hasil Analisis diskriptif}

Pada bagian membahas tentang analisis data dan hasil penelitian tentang pengaruh persepsi kemudahan (Perceived Ease Of Use) (x1), persepsi kegunaan (Perceived Usefulness) (x2), sikap menggunakan simpus (Attitude Toward Using) (x3), niat perilaku menggunakan simpus (Behavioral Intention To Use) (x4), penggunaan SIMPUS sesungguhnya (Actual Use) (x5), terhadap penerimaan SIMPUS (Acceptance Simpus)(y).hasil pengolahan data distribusi variabel peneliatian dengan SPSS menunjukan bahwa persepsi kemudahan (perceived ease of use) (x1) sebagian besar pada kategori cukup sebesar 24 (45,3\%), baik sebesar 20 (37,7\%), kurang sebesar 9 (17,0\%),persepsi kegunaan (perceived usefulness) (x2) sebagian besar pada kategori cukup 26(49,1\%), baik $19(35,7 \%)$, kurang $8(15,1 \%)$, kemudian pada sikap menggunakan simpus (attitude toward using) (x3), sebagain besar cukup sebesar 37 (69,8\%), baik 9 (17,0\%), kurang sebesar $7(13,2 \%)$, niat perilaku menggunakan simpus (behavioral intention to use) $(\mathrm{x} 4)$, sebagian besar pada kategori baik sebesar 22 (41,5\%), cukup 21(39,6\%), kurang 10 (18,9\%). Pada penggunaan simpus sesungguhnya (actual use) (x5), sebagaian besar pada kategori cukup 33 $(62,3 \%)$, baik $14(26,4 \%)$, kurang sebesar 6(11,3\%). Pada penerimaan simpus (acceptance simpus)(y) sebagian besar pada kategori baik 28 (52,8\%), cukup 20 (37,7\%), kurang $5(9,4 \%)$. Berikut pada tabel 5,6 dan juga gambar 2 yang dihasilkan pada hasil diskriftif.

Tabel 5. Nilai mean, sd, minimal, maksimal data penelitian

\begin{tabular}{lllllll}
\hline Nilai statistik & X1 & X2 & X3 & X4 & X5 & Y \\
\hline Mean & 20,88 & 21,05 & 19,88 & 10,75 & 20,92 & 22,81 \\
SD & 3,41 & 3,53 & 2,79 & 2,29 & 3,26 & 3,96 \\
\hline
\end{tabular}

Tabel 6. Distribusi variabel penelitian

\begin{tabular}{|c|c|c|c|c|c|c|c|c|c|}
\hline \multirow[t]{2}{*}{ No } & \multirow[t]{2}{*}{ Variabel } & \multicolumn{2}{|c|}{ Baik } & \multicolumn{2}{|c|}{ Cukup } & \multicolumn{2}{|c|}{ Kurang } & \multicolumn{2}{|c|}{ Total } \\
\hline & & $\mathrm{N}$ & $\%$ & $\mathrm{~N}$ & $\%$ & $\mathrm{~N}$ & $\%$ & $\mathrm{~N}$ & $\%$ \\
\hline 1 & $\begin{array}{l}\text { Persepsi kemudahan (perceived } \\
\text { ease of use) (X1) }\end{array}$ & 20 & 37,7 & 24 & 45,3 & 9 & 17,0 & 53 & 100 \\
\hline 2 & $\begin{array}{l}\text { Persepsi kegunaan (perceived } \\
\text { usefulness) (X2) }\end{array}$ & 19 & 35,7 & 26 & 49,1 & 8 & 15,1 & 53 & 100 \\
\hline 3 & $\begin{array}{l}\text { Sikap menggunakan SIMPUS } \\
\text { (attitude toward using) (X3), }\end{array}$ & 9 & 17,0 & 37 & 69,8 & 7 & 13,2 & 53 & 100 \\
\hline 4 & Niat perilaku menggunakan & 22 & 41,5 & 21 & 39,6 & 10 & 18,9 & 53 & 100 \\
\hline
\end{tabular}

SIMPUS (Behavioral intention to use) (X4) 
$5 \quad$ Penggunaan SIMPUS

Sesungguhnya

(Actual Use) (X5),

6 Penerimaan SIMPUS (Acceptance SIMPUS)(Y) $\begin{array}{llllllll}14 & 26,4 & 33 & 62,3 & 6 & 11,3 & 53 & 100\end{array}$

$28 \quad 52,8 \quad 20$

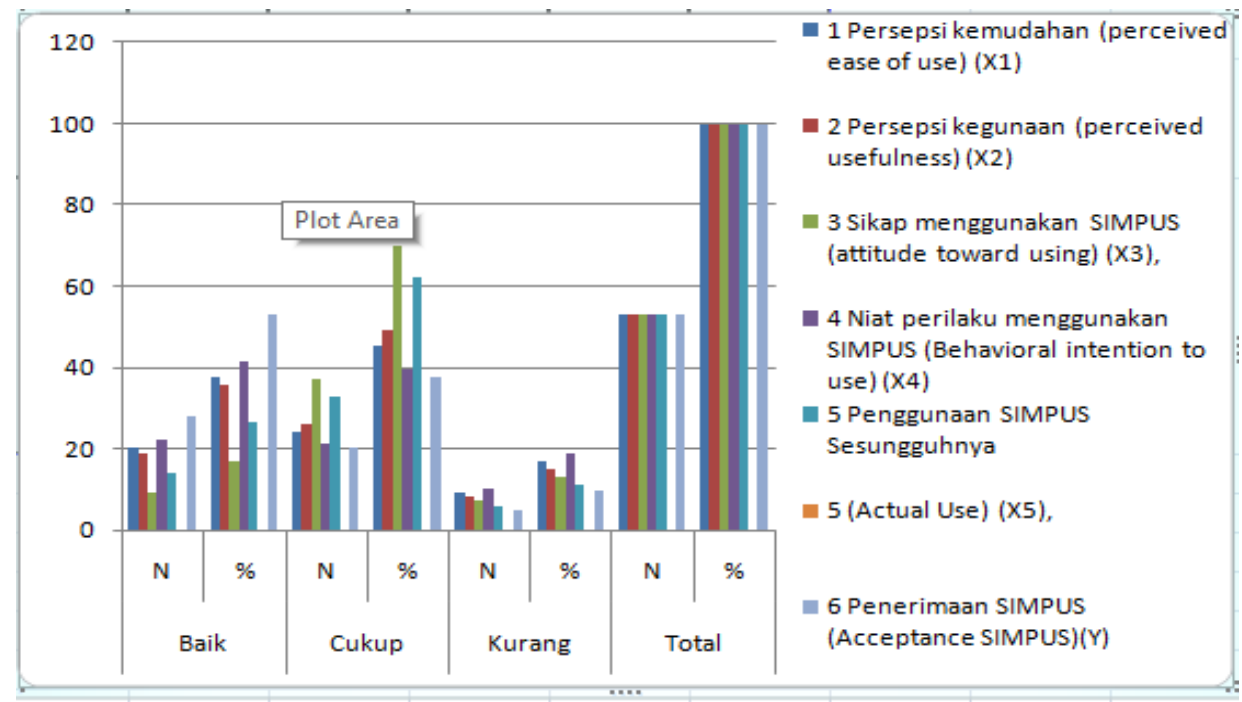

Gambar 2. Grafik distribusi variabel penelitian

4.3. Analisis Regresi Berganda

Tahap uji dalam penelitian ini meliputi tahap pengujian:

A. Uji Normalitas

Tabel 7. One-sample kolmogorov-smirnov test

\begin{tabular}{|c|c|c|c|c|c|c|c|}
\hline & & 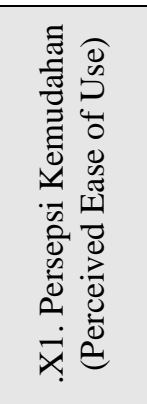 & 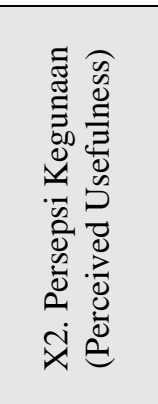 & 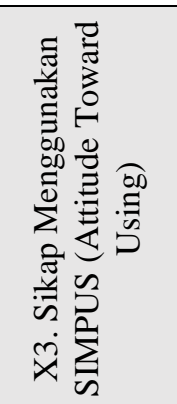 & 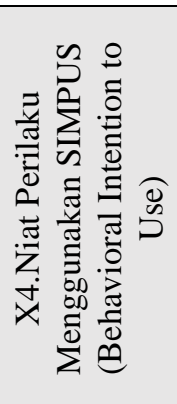 & 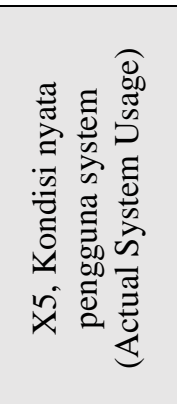 & 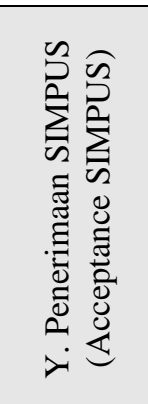 \\
\hline \multicolumn{2}{|l|}{$\mathrm{N}$} & 53 & 53 & 53 & 53 & 53 & 53 \\
\hline Normal & Mean & 20,8868 & 21,0566 & 19,8868 & 10,7547 & 20,9245 & 22,8113 \\
\hline Parameters ${ }^{\mathrm{a}, \mathrm{b}}$ & $\begin{array}{l}\text { Std. } \\
\text { Deviation }\end{array}$ & 3,41186 & 3,53779 & 2,79877 & 2,29469 & 3,26313 & 3,96163 \\
\hline Most Extreme & Absolute & ,152 &, 152 &, 158 &, 164 & , 181 & ,106 \\
\hline \multirow[t]{2}{*}{ Differences } & Positive & ,094 &, 108 & ,092 &, 105 & ,107 & ,076 \\
\hline & Negative &,- 152 &,- 152 &,- 158 &,- 164 &,- 181 &,- 106 \\
\hline \multicolumn{2}{|c|}{ Kolmogorov-Smirnov Z } & 1,108 & 1,109 & 1,148 & 1,191 & 1,317 & ,771 \\
\hline \multicolumn{2}{|c|}{ Asymp. Sig. (2-tailed) } & ,172 &, 171 & 143 & ,117 &, 062 &, 592 \\
\hline
\end{tabular}


Pada tabel 7 menjelaskan mengenai hasil uji normalitas dengan menggunakan uji kolmogorov - smirnov $(\mathrm{k}-\mathrm{s})$ pada data ke enam variabel berdistribusi normal (nilai sig $>0.05$ ) yaitu x1 $(\mathrm{p}=0,172), x 2(\mathrm{p}=0,171), x 3(\mathrm{p}=0,143), x 4(\mathrm{p}=0,117), x 5(\mathrm{p}=0,062), y(\mathrm{p}=0,592)$.

\section{B. Uji Linieritas}

Hasil uji linearitas dengan menggunakan uji durbin watson menunjukkan bahwa tidak ada korelasi antar sisaan/eror atau asumsi terpenuhi bahwa fungsi linier yaitu nilai statistik durbin watson $(1,722)$ terletak diantara nilai tabel durbin watson $(1,703)$ dan $4-\mathrm{du}(2,291)$.

\section{Uji Multikolinieritas (Independensi).}

Hasi uji multikolinieritas menunjukkan bahwa tidak ada satu pun variabel bebas yang memiliki nilai vif(variance inflation factor) lebih dari 10 atau nilai toleransi kurang dari 0,10 .

\section{Hasil Analisis Regresi Multiple}

Bahwa nilai $f_{\text {hitung }}=91,469>f_{\text {tabel }}=2,65$ atau nilai $p<0,05$ sehingga ho ditolak artinya koefisien regresi ganda signifikan. Jadi variabel $\mathrm{x}_{1}, \mathrm{x}_{2}, \mathrm{x}_{3}, \mathrm{x}_{4}, \mathrm{x}_{5}$ berpengaruh secara simultan atau bersama - sama dan signifikan terhadap penerimaan SIMPUS. Hasil uji $f$ dapat dilihat dilampiran8 tabel anova.

Uji secara individual/partial ditunjukkan pada nilai $t$, nilai $t_{\text {hitung }}>t$ tabel $(2,021)$ pada $x_{1}, x_{2}, x_{3}$ atau nilai $\mathrm{p}<0,05$ sehingga ho ditolak yang berarti variabel $\mathrm{x}_{1}, \mathrm{x}_{2}, \mathrm{x}_{3}$ secara individual dan signifikan berpengaruh terhadap penerimaan SIMPUS. Sedangkan variabel $\mathrm{x}_{4}, \mathrm{x}_{5}$ mempunyai niliai $\mathrm{p}>0.05(0,190 ; 0,742)$ sehingga $\mathrm{h} 0$ diterima yang berarti secara individual/partial variabel $\mathrm{x}_{1}, \mathrm{x}_{2}, \mathrm{x}_{3}$ tidak berpengaruh terhadap penerimaan simpus.nilai $\mathrm{r}$ square $=90,7 \%$ penerimaan simpus dapat dijelaskan oleh variabel $\mathrm{x}_{1}, \mathrm{x}_{2}, \mathrm{x}_{3}, \mathrm{x}_{4}, \mathrm{x}_{5}$.

\section{KESIMPULAN}

Penelitian ini melibatkan lima variabel bebas dan satu variabel terikat dan lima hipotesis dari variabel tersebut.tiga hipotesis ditolak dan dua hipotesis diterima.membuktikan bahwa kemudahan dalam menggunakan sistem informasi yang telah diterapkan berpengaruh terhadap persepsi pegawai tentang kegunaan sistem informasi yang diterapkan dalam lingkungan kerjanya. Hubungan antara persepsi kegunaan (Perceived Usefulness) terhadap persepsi penerimaan SIMPUS (Acceptance SIMPUS) benar-benar berpengaruh nyata terhadap penerimaan SIMPUS dalam menggunakan apalikasi SIMPUS. Selanjutnyapersepsi kegunaan (Perceived Usefulness) SIMPUS berpengaruh positif terhadap persepsi penerimaan SIMPUS (Acceptance SIMPUS) pada pengguna teknologi informasi berpengaruh pada pengguna. Hubungan antara sikap menggunakan simpus terhadap penerimaan SIMPUS. Sikap menggunakan sangat berpengaruh terhadap penerimaan SIMPUS. Hubungan antara niat perilaku menggunakan SIMPUS (Behavioral Intention To Use) tidak berpengaruh terhadap penerimaan simpus. Dan penggunaan SIMPUS sesungguhnya (Actual Use) tidak berpengaruh terhadap penerimaan SIMPUS dalam penggunaan aplikasi SIMPUS. Hasil dari keseluruhan aspekpersepsi kemudahan, persepsi kegunaan, sikap menggunakan, memberikan pengaruh nyata terhadap penerimaan SIMPUS. Sedangkan niat perilaku menggunakan,penggunaan SIMPUS sesungguhnya tidak berpengaruh terhadap penerimaan SIMPUS. Dari kelima variabel hanya mampu menjelaskan pengaruh terhadap penerimaan SIMPUS sebesar 90,7\% . 


\section{SARAN}

Pada penelitian ini dihasilkan analisis yang baik. Dalam penggunaan tam perlu adanya modifikasi antar variabel supaya mendapatkan hasil yang lebih terstruktur.

\section{DAFTAR PUSTAKA}

[1] P. data dan Informasi, "SIKDA Generik," Bul. Jendela Data dan Inf. Kesehat., pp. 1-8, 2011.

[2] Natalia Tangke, "Analisa Penerimaan Penerapan Teknik Audit Berbantuan Komputer (TABK) dengan Menggunakan Technology Acceptance Model (TAM) pada Badan Pemeriksa Keuangan (BPK) RI," J. Akunt. Keuang., vol. 6, no. 1, pp. 10-28, 2016.

[3] F. D. Davis, "Perceived usefulness, perceived ease of use, and user acceptance of information technology," MIS Q. Manag. Inf. Syst., vol. 13, no. 3, pp. 319-339, 1989, doi: 10.2307/249008.

[4] Z. Dulcic, D. Pavlic, and I. Silic, "Evaluating the Intended Use of Decision Support System (DSS) by Applying Technology Acceptance Model (TAM) in Business Organizations in Croatia," Procedia - Soc. Behav. Sci., vol. 58, pp. 1565-1575, Oct. 2012, doi: 10.1016/j.sbspro.2012.09.1143.

[5] T. Farahat, "Applying the Technology Acceptance Model to Online Learning in the Egyptian Universities," Procedia - Soc. Behav. Sci., vol. 64, pp. 95-104, Nov. 2012, doi: 10.1016/j.sbspro.2012.11.012.

[6] I. Santouridis and M. Kyritsi, "Investigating the Determinants of Internet Banking Adoption in Greece," Procedia Econ. Financ., vol. 9, pp. 501-510, 2014, doi: 10.1016/s2212-5671(14)00051-3.

[7] M. G. Morris and A. Dillon, "How user perceptions influence software use," IEEE Softw., vol. 14, no. 4, pp. 58-64, 1997, doi: 10.1109/52.595956.

[8] S. S. Al-Gahtani, "Modeling the electronic transactions acceptance using an extended technology acceptance model," Appl. Comput. Informatics, vol. 9, no. 1, pp. 47-77, Jan. 2011, doi: 10.1016/j.aci.2009.04.001.

[9] B. Sekaran, U. and Roger, Research Methods for Busines. 2014.

[10] F.-C. Lo, J.-C. Hong, M.-X. Lin, and C.-Y. Hsu, "Extending the Technology Acceptance Model to Investigate Impact of Embodied Games on Learning of Xiao-zhuan()," Procedia - Soc. Behav. Sci., vol. 64, pp. 545-554, Nov. 2012, doi: 10.1016/j.sbspro.2012.11.064.

[11] Jogiyanto, Sistem Informasi Keperilakuan. Yogyakarta: Andi, 2007. 